\title{
Multimodal and multilevel approaches: key elements in preventive interventions
}

\author{
Ulla Walter • Elisabeth Pott • Silke Pawils
}

Published online: 15 February 2012

(C) Springer-Verlag 2012

The social context in which children develop is a key determinant of their health. The social background tells us something about a child's welfare and chances of growing up healthy. Moreover, it gives us clues as to which target groups should be a particular focus of our attention when implementing preventive interventions (Marmot et al. 2010). Children from low-income families with low education levels generally have poorer health and more psychological problems than their age-matched peers from highincome families with higher education levels. Thus, education level is an important factor. There is a reciprocal relationship between education and health. A recent review of over 50 publications by the World Health Organization revealed some interesting findings (Suhrcke and de Paz 2011) - good general health during childhood has a positive effect on education background and educational

\footnotetext{
U. Walter $(\bowtie)$

Institut für Epidemiologie, Sozialmedizin und

Gesundheitssystemforschung,

Medizinische Hochschule Hannover,

Carl-Neuberg-Str. 1,

30625 Hannover, Germany

e-mail: Walter.Ulla@MH-Hannover.de

E. Pott

Bundeszentrale für gesundheitliche Aufklärung, Ostmerheimer Straße 220,

51109 Köln, Germany

\section{S. Pawils}

Institut für Medizinische Psychologie, W26,

Universitätsklinikum Hamburg-Eppendorf,

Martinistraße 52,

20246 Hamburg, Germany
}

attainment. Consequently, poor health has a negative effect on education for the individual child. Children in poor health spend up to one-third more time in the school system than healthy children, and healthy children complete school with higher levels of education. Furthermore, it was shown that poor nutrition and smoking in particular have a negative effect on education. Likewise, the evidence indicates that obesity and overweight are negatively associated with educational outcomes, and that frequent sleeping problems in childhood can hinder academic performance. Conversely, physical activity has a positive impact on academic performance. By comparison, the effects of anxiety and depression on education are under-researched. The authors conclude that the available data provides sufficient evidence for the influence of health on education. Their findings underline the need to invest not only in the education of children, but also in their health and in prevention chains, particularly at the local level, right from the beginning.

One-dimensional models do not adequately reflect the complexity of factors involved here. Models for the prevention of overweight and obesity, the etiology of which is not completely understood, made this extremely clear. WeimerJehle, Deuschle and Rehaag, who created a causal loop model to identify key factors for prevention in socially disadvantaged children and adolescents, concluded that there is no one specific factor that can be expected to act as an effective prevention factor for every scenario. Instead, a multi-level perspective is needed which takes into account the specific characteristics of an individual's environment.

Behavioural and structural prevention strategies exist, and Pawils, Atabaki, Metzner, Nöcker, Linden, Plaumann and Walter provide an overview of the German and European approaches. Other examples are shown in the different 
articles published in this special issue. They were implemented in different settings (kindergartens, schools and communities) and use different routes of access (hospitals, professionals and peers). Structure building is frequently an important aspect of networking.

The current issue focussing on behavioural and structural interventions supplements the previous special issue on structured programmes published in 2011. All studies published in this issue were funded under the German Ministry of Education and Research's (BMBF) national prevention and research initiative focussing on new evidence-based and implementation-oriented research processes. From 2004 to 2012, the BMBF sponsored 60 preventive intervention projects, 36 of which targeted children and adolescents. The design and development of new interventions, the testing of new access paths, and the evaluation of efficacy and quality assurance are central elements of these research projects. They aim to create new structures and integrate them in existing structures in order to enhance sustainability. A major prerequisite was to achieve cooperation between researchers and professionals in the field during the planning and implementation of the research projects to ensure that the results would be highly relevant to practice. The Cooperation for Sustainable Prevention (KNP), a metaproject conducted by three centres - Hannover Medical School (MHH), the University Medical Centre HamburgEppendorf (UKE), and the Federal Centre for Health Education $(\mathrm{BZgA})$ in Cologne - in collaboration with the Association for Health Promotion and Academy for Social Medicine Lower Saxony, the Bavarian Health and Food Safety Authority, and the German Society for Social Medicine and Prevention serves to support networking and to promote the dissemination of research findings among researchers, health professionals and policy-makers.

In particular, this special issue provides insight into the individual interventions themselves in response to the repeated demands for differentiated descriptions (Schulz et al. 2011). Some of the studies focus on target groups that are under-researched and which have received little attention in professional health and preventive care until now. These include the children of mentally ill parents, who have a high risk of developing mental disorders and behavioural problems. The Kanu Program presented by Heitmann, Schmuhl, Reinisch and Bauer has multiple coordinated elements designed to support these children and their parents, to train professionals and support networking, and to provide godparents for the children. This type of multimodal approach is characteristic of many preventive intervention studies.

Over the past few years, growing interest has been shown in health-related topics at kindergartens. In Germany, it is typical to have a large number of individual projects with a variety of different pedagogical approaches but little networking and cooperation between the individual projects
(Kliche et al. 2008). Evaluated preventive intervention programmes and measures for this target group are scarce. Fröhlich-Gildhoff and Rönnau-Böse address this problem in a preventive intervention programme designed to promote resilience, that is, to enhance the affected children's ability to manage crises and development tasks.

"Baloo and You", a mentoring program that targets primary school children with disadvantaged family backgrounds and personal and development problems, is designed to strengthen these children's basic life skills. Drexler, Borrmann and Müller-Kohlenberg provide a detailed description of the project and its preliminary results.

Menrath, Müller-Godeffroy, Prüßmann, Ravens-Sieberer, Ottava, Prüßmann, Erhart, Hillebrandt and Thyen describe a multi-centre study evaluating school-based life skills programmes for the prevention of smoking. Pieper, Weber, Markgraf-Stiksrud, Stein, Heinzel-Gutenbrunner and Jablonski-Momeni address the issue of oral health and describe a 6-year preventive intervention for 12-year-old students. Both interventions yielded positive effects.

Gesund Leben Lernen (Learn to Live Healthy), a statewide intervention in Lower Saxony, uses the balanced scorecard (BSC), which is best known as a corporate development instrument. The aim of using the BSC is to strengthen the focus on health-promoting schools by defining and making their goals more concrete. Liersch, Sayed, Windel, Altgeld, Krauth and Walter present a version of the balanced scorecard that was adapted to the specific needs of school reality and designed for use in schools.

Apart from providing access to services through institutions (e.g., hospitals) and settings (e.g., kindergartens and schools), the use of peer support is also recommended. This approach was taken by one borough in Berlin, where "community mothers" were trained to reach out to disadvantaged families through home visits and family cafés. This proved to be especially beneficial to the community mothers themselves. Stolzenfels, Berg and Maschewsky-Schneider discuss key success factors for peer access as well as its clear limitations. Their results plainly show that successful cooperation between peer-based and professional-based systems is feasible but requires a great deal of effort on both sides as well as political support.

Access to disadvantaged women via mediators is the focus of GO-Healthy Living in East Leipzig, the project conducted by Große, Daufratshofer, Igel and Grande. Limitations on access were also observed in this project. The investigators concluded that outreach to mothers with immigrant backgrounds was good, whereas mothers with low education levels were more difficult to reach.

Süß and Trojan developed an integrated approach to inter-sectoral coalitions of actors in Lenzsiedlung, a social housing area in Hamburg. Their dynamic work features a participatory and integrative (setting) approach in which a 
preventive intervention was planned and integrated at the round table. Key criteria for integrated approaches are discussed by the authors.

The current special issue provides a rather impressive overview of the German preventive intervention landscape and research on this topic, which also does not shy away from complex interventions. Furthermore, this issue shows the enormous time and effort invested in these studies and in their practical implementation. If this preventive work is to be sustainable, it will be just as essential to secure political support as it is to integrate prevention programmes into the existing education, social services and health-care structural landscape and to refine the methods used to evaluate these complex strategies.

\section{Reference}

Kliche et al (2008) Prävention und Gesundheitsförderung in Kindertagesstätten. Eine Studie zu Determinanten, Verbreitung und Methoden für Kinder und Mitarbeiterinnen. Juventa Verlag, Weinheim und München, Germany

Marmot et al (2010) Fair society, healthy lives: strategic review of health inequalities in England post 2010. The Marmot Review. www.marmotreview.org. Cited February 2007

Schulz KF, Altman DG, Moher D (2011) CONSORT 2010: Aktualisierte Leitlinie für Berichte randomisierter Studien im ParallelgruppenDesign. Deutsche Medizinische Wochenschrift 136:e20-e23

Suhrcke M, de Paz NC (2011) The impact of health and health behaviours on educational outcomes in high-income countries: a review of the evidence. WHO Regional Office for Europe, Copenhagen 